\title{
Audiological Profile of Patients with Vitiligo
}

\author{
Yasmeen A. Mohamed, Mohamed W. Mustafa, Mohamed A. El-Hamd and \\ Mohamed Abd Al-Ghaffar \\ Department of Audiology unit, Sohag Faculty of Medicine, Sohag University
}

\begin{abstract}
Introduction: Vitiligo is an acquired hypomelanotic disorder characterized by circumscribed depigmented macules or patches resulting from loss of functional melanocytes and of melanin from the epidermis. The affection of extracutaneous melanocytes in some vitiligo patients suggests that systemic immunological reactions directed at pigment cells might play a role in the development of the disease.

Aim of the work: Evaluation of the cochlea and the auditory nerve in vitiligo patients.

Patients and Methods: Cross sectional clinical study included total number of 60 subjects were examined. All subjects included were subjected to the following procedures: Full history taking, clinical examination, Basic audiologic evaluation, Transient Evoked otoacoustic emissions (TEOAEs), Distortion Product Otoacoustic Emission (DPOAE), Auditory Brainstem Response test (ABR).

Results: The ABR finding concluded that melanin play a significant role in establishment and maintenance of structure and function of the auditory system and may modulate the transduction of auditory stimuli by the inner ear.

Conclusion: TEOAE and DPOAE are sensitive tests for detecting cochlear dysfunction before symptoms become manifested as the TEOAE and DPOAE were impaired in 35\% and $35 \%$ of the ears with normal hearing.
\end{abstract}

Key words: Audiological profile, vitiligo.

\section{Introduction}

Vitiligo is an acquired hypomelanotic disorder characterized by circumscribed depigmented macules or patches resulting from loss of functional melanocytes and of melanin from the epidermis ${ }^{(1)}$. Vitiligo is not transmitted by simple Mendelian mechanism and its inheritance pattern is more consistent with that of a polygenic trait ${ }^{(2)}$.

Many possible causes of vitiligo have been proposed, including stress, infections, mutations, neural factors, melatonin receptor dysfunction, and impaired melanocyte migration and/or proliferation. In addition, the accumulation of toxic intermediate products of melanin synthesis ${ }^{(3)}$, the breakdown of free radical defense ${ }^{(4)}$ and the build up of excessive quantities of hydrogen peroxide have all been suggested to result in the selfdestruction of pigment cells ${ }^{(4)}$.

Although loss of melanocytes from the skin is almost always the primary and initial symptom in vitiligo, other pigment cells in the body can be affected. Melanocytes are located in the inner ear and vitiligo associated auditory problems have been reported is some patients ${ }^{(5)}$.

Damage can also occur to melanocytes within the eye. The affection of extracutaneous melanocytes in some vitiligo patients suggests that systemic immunological reactions directed at pigment cells might play a role in the development of the disease ${ }^{(1)}$.

\section{Aim of the work:}

Evaluation of the cochlea and the auditory nerve in vitiligo patients.

\section{Patients and Methods: Procedure:}

First Informed written consent was taken from the parents before entrance of the operating room and study was approved by ethics committee in Sohag medical university.

Design: Cross sectional study. 


\section{Patients:}

A total number of 60 subjects were examined in this study.

They were divided into two main groups;-

\section{1- Control group:}

It composed of 30 persons who had no vitiligo, no complaints of hearing loss and no history of ear infections, trauma, use of ototoxic drugs or history of familial hearing loss were selected for the study. They were 6 males and 24 females. Their age ranged from 16- 40 years. They were chosen from those accompanying patients attending Audiology unit sohag university.

\section{Study group:}

It composed of 30 vitiligo patients. They were 8 males and 22 females. Their age ranged from 17-46. years. The duration of the disease ranged from 4 months to 35 years. The age of onset ranged from 4-44 years. They were selected from dermatology clinic, sohag university. Audiological evaluation were done at Audiology unit, sohag universty.

The study group was divided as the following;

According to type of vitiligo into:

- Generalized vitiligo: they were 17 patients.

- Localized vitiligo: they were 13 patients

According to family history of vitiligo into:

- Patients with positive family history they were 11 patients

$\circ(36.7 \%)$.

- Patients with negative family history they were 19 patients

○ $(63.3 \%)$.

According to age of onset into:

- Patients with age of onset of vitiligo $<20$ years old (subgroup A).

- Patients with age of onset of vitiligo 20-30 years old (subgroup B).

- Patients with age of onset of vitiligo $\geq 30$ years old (subgroup C).
According to duration of vitiligo into:

- Patients with duration of vitiligo $<10$ years.

- Patients with duration of vitiligo $\geq 10$ years.

According to Skin type into :

- Patients with skin type III: They were 19 patients $(63.3 \%)$.

- Patients with skin type IV: They were 11 patients (36.7)

\section{Methods:}

All subjects included were subjected to the following procedures:

1. Full history taking:

including personal history, history of hearing loss,,tinnitus, vertigo, history to exclude any otological or neuro - otological diseases

\section{Clinical examination:}

including otologic examination, and skin examination.

3. Basic audiologic evaluation: including:

a) Pure tone audiometry; in the form of: Air conduction in the frequency range of $250-8000 \mathrm{~Hz}$. Bone conduction in the frequency range of $500-4000 \mathrm{~Hz}$.

b) Speech audiometry; including: Speech reception threshold (SRT), using Arabic spondaic words. word discrimination score (WDS), using Arabic phonetically balanced (PB) words.

c) Immittancemetry: including single-component, single- frequency tympanometry with a probe tone of $226 \mathrm{~Hz}$ and testing of the acoustic reflex threshold for the ipsilateral and the contralateral elicited reflexes, using pure tones at frequencies 500, 1000, 2000 and $4000 \mathrm{~Hz}$.

The measurements following those were made after acoustic immittance assessments, which were used to demonstrate that middle-ear function was normal at the time of the TEOAE test. 
4) Transient Evoked otoacoustic emissions (TEOAEs).

TEOAEs were elicited using non-linear click stimuli at stimulus intensity ranges from $80 \mathrm{~dB}$ peak equivalent sound pressure level (SPL), 80 us duration, at a rate of 50 clicks per second, within a time window of 20 msec. TEOAEs were analyzed by recording 260 sweeps in one session and averaged within 5 frequency bands centered at $(1,1.5,2,3$ and $4 \mathrm{KHz})$. The differential non-linear test paradigm was used. The stimulus was characterized by a train of four clicks, three with the same amplitude and polarity, followed by a fourth one with 3 -fold greater amplitude and an opposite polarity. Responses were represented by an average of a maximum of 260 click stimuli trains (1040) stored into two different buffers averaged separately (A and B) for a total of 2080 clicks. The averaged amplitude in $\mathrm{dB}$, of these two waveforms presented the overall echo level in $\mathrm{dB}$ SPL. In addition the reproducibility of TEOAEs was tested by the correlation between signals from the two buffets. All responses were stored for analyses.

\section{5) Distortion Product} Otoacoustic Emission (DPOAE).

DPOAEs occur in response to two simultaneous tone of different frequencies presented to the ear the lower frequency tone is called F1and the higher frequency tone is called F2. F2 is frequently ,but not always, 1.21 times the frequency of F1. In response to F1 and F2 presentation, the ear generates other tones of different frequencies but with a clear frequency relationship to F1and $F$ 2. these generated tones are called distortion products. the largest distortion product is usually at the frequency that is two time the frequency of $\mathrm{F} 1$ minus the frequency of F2 or (2F1-F2). Although $2 \mathrm{~F} 1-\mathrm{F} 2$ is of a much lower frequency than either $F 1$ or $F 2$, the presence /absence and /or amplitude of the 2F1F2 component correlates most closely with hearing thresholds at either the F2 frequency or approximately the midpoint between the F1 and F2 frequencies called geometric mean.

\section{6) Auditory}

Response test (ABR).

-Skin preparation and electrode montage:

The skin over the forehead and mastoids was prepared and cleaned by alcohol to reduce electrode impedance. Four disposable electrodes were fixed according to the Smart EP manual specification as follows: one high frontal $\mathrm{Fz}$ (positive electrode), one low frontal Fpz (ground electrode). The last two electrodes were placed on the left and right mastoids (as negative electrode or reference electrode) depending on the recording side. All electrodes were connected to the preamplifier of the Smart EP equipment.

\section{Exclusion criteria:}

- A history of any middle ear disease, previous ear surgery, familial hearing loss, ototoxic drug intake, chronic noise exposure and head trauma.

- The presence of any systemic disease such as diabetes or hypertension.

- Patient with age more than 70 years. 


\section{Results}

Table ( 1 ) Age and gender distribution of the control group and the study group.

\begin{tabular}{llllrl}
\hline & & Control & Study group & t-test & P \\
& & No $=30$ & No $=30$ & & Value \\
\cline { 2 - 6 } Age & & Mean \pm SD & Mean \pm SD & & \\
Gender & M & $21.40 \pm 10.10$ & $25.26 \pm 12.58$ & 1.184 & .236 \\
\cline { 2 - 4 } & F & 80.0 & 26.7 & 0.373 & .542 \\
\hline
\end{tabular}

Table ( 2 ): Comparison between pure tone threshold of control group and family history of vitiligo subgroups .

\begin{tabular}{lllllll}
\hline $\begin{array}{l}\text { Freq. } \\
\text { Bands }\end{array}$ & Side & $\begin{array}{l}\text { Control } \\
\mathbf{( 3 0})\end{array}$ & \multicolumn{2}{l}{ Family history } & F & $\begin{array}{l}\text { P } \\
\text { value }\end{array}$ \\
\cline { 4 - 5 } & & & $\begin{array}{l}\text { Positive } \\
\mathbf{( 1 1})\end{array}$ & $\begin{array}{l}\text { Negative } \\
\mathbf{( 1 9 )}\end{array}$ & & \\
50 & $\mathrm{R}$ & $10.00 \pm 5.25$ & $13.18 \pm 3.37$ & $9.74 \pm 4.24$ & 2.250 & 0.115 \\
& $\mathrm{~L}$ & $10.00 \pm 4.55$ & $10.46 \pm 4.16$ & $10.00 \pm 4.71$ & 0.045 & 0.956 \\
500 & $\mathrm{R}$ & $10.33 \pm 4.72$ & $13.64 \pm 3.23$ & $10.00 \pm 5.27$ & 2.440 & 0.096 \\
& $\mathrm{~L}$ & $10.00 \pm 4.15$ & $13.18 \pm 4.62$ & $11.58 \pm 3.75$ & 2.605 & 0.083 \\
1000 & $\mathrm{R}$ & $10.67 \pm 4.50$ & $10.91 \pm 5.39$ & $10.26 \pm 4.56$ & 0.076 & 0.927 \\
& $\mathrm{~L}$ & $10.67 \pm 4.10$ & $10.91 \pm 3.75$ & $10.79 \pm 3.82$ & 0.017 & 0.984 \\
2000 & $\mathrm{R}$ & $9.00 \pm 4.62$ & $10.91 \pm 4.91$ & $9.21 \pm 3.82$ & 0.774 & 0.466 \\
& $\mathrm{~L}$ & $12.00 \pm 3.62$ & $13.18 \pm 4.05$ & $10.26 \pm 4.85$ & 1.945 & 0.152 \\
4000 & $\mathrm{R}$ & $11.33 \pm 4.72$ & $10.91 \pm 4.37$ & $11.32 \pm 4.96$ & 0.035 & 0.966 \\
& $\mathrm{~L}$ & $11.67 \pm 4.80$ & $13.64 \pm 6.74$ & $10.79 \pm 5.34$ & 0.992 & 0.377 \\
8000 & $\mathrm{R}$ & $11.67 \pm 4.01$ & $15.46 \pm 6.88$ & $11.84 \pm 5.82$ & 2.292 & 0.110 \\
\cline { 2 - 5 } & $\mathrm{L}$ & $11.00 \pm 3.81^{\mathrm{a}}$ & $16.36 \pm 7.10^{\mathrm{a}}$ & $11.32 \pm 5.97^{\mathrm{b}}$ & 4.510 & $0.015^{*}$ \\
& & & $\mathrm{~b}$ & & & \\
\hline
\end{tabular}


Table (3) : Comparison between TEOAE -SNR of control group and age of onset of vitiligo subgroups.

\begin{tabular}{|c|c|c|c|c|c|c|c|}
\hline \multirow{2}{*}{$\begin{array}{l}\text { Freq } \\
\text { band } \\
s\end{array}$} & \multirow{2}{*}{$\begin{array}{l}\text { Sid } \\
\text { e }\end{array}$} & \multirow{2}{*}{$\begin{array}{l}\text { Control } \\
\text { ( } \mathbf{3 0})\end{array}$} & \multicolumn{3}{|c|}{ Age of onset } & \multirow[t]{2}{*}{$\mathbf{F}$} & \multirow{2}{*}{$\begin{array}{l}P \\
\text { value }\end{array}$} \\
\hline & & & $<20 y(A)$ & $\begin{array}{l}20-30 y \\
\text { B) }\end{array}$ & $\geq 30 y(C)$ & & \\
\hline \multirow[t]{2}{*}{1000} & $\mathrm{R}$ & $\begin{array}{l}8.33 \pm 5.2 \\
5\end{array}$ & $8.24 \pm 5.86$ & $9.60 \pm 2.61$ & $8.25 \pm 5.92$ & 0.092 & 0.964 \\
\hline & $\mathrm{L}$ & $\begin{array}{l}9.73 \pm 7: 6 \\
7\end{array}$ & $8.12 \pm 5.97$ & $8.20 \pm 4.32$ & $7.63 \pm 5.15$ & 0.343 & 0.794 \\
\hline \multirow[t]{2}{*}{1500} & $\mathrm{R}$ & $\begin{array}{l}12.07 \pm 6 . \\
22\end{array}$ & $\begin{array}{l}13.53 \pm 4.1 \\
2\end{array}$ & $\begin{array}{l}12.40 \pm 8.2 \\
6\end{array}$ & $\begin{array}{l}11.38 \pm 5.9 \\
5\end{array}$ & 0.326 & 0.807 \\
\hline & $\mathrm{L}$ & $\begin{array}{l}11.13 \pm 4 . \\
44\end{array}$ & $11.76 \pm 4.44$ & $9.40 \pm 2.07$ & $\begin{array}{l}14.25 \pm 4.3 \\
7\end{array}$ & 0.498 & 0.685 \\
\hline \multirow[t]{2}{*}{2000} & $\mathrm{R}$ & $\begin{array}{l}13.13 \pm 7 . \\
72\end{array}$ & $\begin{array}{l}14.94 \pm 5.1 \\
5\end{array}$ & $\begin{array}{l}.13 .40 \pm 5.3 \\
2\end{array}$ & $\begin{array}{l}12.75 \pm 7.6 \\
3 .\end{array}$ & 0.301 & 0.825 \\
\hline & $\mathrm{L}$ & $\begin{array}{l}13.13 \pm 5 \\
26\end{array}$ & $14 \pm 6.18$ & $\begin{array}{l}15.40 \pm 7.8 \\
9\end{array}$ & $\begin{array}{l}13.25 \pm 7.4 \\
2\end{array}$ & 0.241 & 0.868 \\
\hline \multirow[t]{2}{*}{3000} & $\mathrm{R}$ & $\begin{array}{l}12.13 \pm 8 \\
17\end{array}$ & $\begin{array}{l}13.29 \pm 6.6 \\
2\end{array}$ & $\begin{array}{l}14.80 \pm 4.5 \\
5\end{array}$ & $9.88 \pm 6.60$ & 0.589 & 0.624 \\
\hline & $\mathrm{L}$ & $\begin{array}{l}11.27 \pm 4 \\
48\end{array}$ & $\begin{array}{l}12.71 \pm 5.5 \\
0\end{array}$ & $\begin{array}{l}14.80 \pm 5.4 \\
5\end{array}$ & $\begin{array}{l}10.88 \pm 7.9 \\
7\end{array}$ & 1.139 & 0.341 \\
\hline \multirow[t]{2}{*}{4000} & $\mathrm{R}$ & $\begin{array}{l}16.87 \pm 4 \\
67^{\mathrm{ab}}\end{array}$ & ${ }_{c} 10.24 \pm 7.0^{\mathrm{a}}$ & $\begin{array}{l}16.20 \pm 3.5 \\
7^{\text {cd }}\end{array}$ & $6.88 \pm 4.49^{b}$ & 10.502 & $\underset{*}{\leq 0.001 *}$ \\
\hline & $\mathrm{L}$ & $\begin{array}{l}15.73 \pm 5 . \\
76^{\mathrm{ab}}\end{array}$ & $8.76 \pm 5.27^{\mathrm{a}}$ & $\begin{array}{l}13.40 \pm 5.4 \\
1\end{array}$ & $8.75 \pm 6.04^{b}$ & 6.989 & $\begin{array}{l}\leq 0.001 * \\
*\end{array}$ \\
\hline
\end{tabular}

Table (4) Measurement of central tendency, dispersion and position, by frequency to the value of amplitude of the distorstion otoacoustic emission Product in the study group.

\begin{tabular}{llllll}
\hline $\begin{array}{l}\text { Freq } \\
\text { bands }\end{array}$ & • Side & Mean & SD & Minimum & Maximum \\
\hline 1000 & $\mathrm{R}$ & 8.58 & 6.71 & -3.2 & 18.6 \\
& $\mathrm{~L}$ & 10.07 & 4.58 & 3.9 & 22 \\
1500 & $\mathrm{R}$ & 15.41 & 7.63 & 1.6 & 26.7 \\
& $\mathrm{~L}$ & 13.78 & 6.01 & 2.3 & 23.1 \\
2000 & $\mathrm{R}$ & 14.63 & 5.61 & 3.2 & 22.3 \\
& $\mathrm{~L}$ & 15.24 & 6.11 & 6.2 & 29.1 \\
3000 & $\mathrm{R}$ & 12.43 & 9.71 & -17.2 & 24.1 \\
& $\mathrm{~L}$ & 14.17 & 6.04 & 6.3 & 23.6 \\
4000 & $\mathrm{R}$ & 19.56 & 6.04 & 6 & 31.4 \\
& $\mathrm{~L}$ & 19.49 & 5.94 & 6.6 & 30.5 \\
8000 & $\mathrm{R}$ & 17.92 & 8.10 & -1 & 33.9 \\
& $\mathrm{~L}$ & 15.8 & 10.4 & -1.6 & 32.7 \\
\hline
\end{tabular}


Table ( 5 ) Mean and SD of auditory brainstem response ( ABR ) latencies in milliseconds of both control and study group .

\begin{tabular}{llllll}
\hline \multirow{2}{*}{$\begin{array}{l}\text { ABR waves } \\
\text { at 90 dB } \\
\text { nHL }\end{array}$} & side & Control group & Study group & t-test & P value \\
\cline { 3 - 4 } & & & & \\
Wave I & Rt & $1.52 \pm 0.0276$ & $1.48 \pm 0.0234$ & 3.314 & $0.002^{* *}$ \\
& Lt & $1.53 \pm 0.025$ & $1.49 \pm 0.027$ & 4.120 & $0.001^{* * *}$ \\
Wave III & Rt & $3.56 \pm 0.0887$ & $3.54 \pm 0.0688$ & 0.935 & $0.012^{*}$ \\
& Lt & $3.36 \pm 0.084$ & $3.35 \pm 0.071$ & 1.550 & $0.011^{*}$ \\
Wave V & Rt & $5.636 \pm 0.110$ & $5.643 \pm 0.128$ & 1.563 & $0.011^{*}$ \\
\cline { 2 - 5 } & Lt & $5.62 \pm 0.105$ & $5.60 \pm 0.086$ & 0.883 & $0.013^{*}$ \\
\hline
\end{tabular}

No statistically significant difference was found between control and study groups as regard age and gender in table $\mathbf{1}$.

Groups with similar superscript letters are statistically significantly different according to post-hoc LSD test $(\mathrm{p} \leq 0.05)$. Statistically significant difference in pure tone threshold between control group \& positive family history subgroup and between positive \&negative family history subgroups at $8 \mathrm{kHz}$ in the left ears $(\mathrm{p}<0.05)$ in table 2.

Groups with similar superscript letters are statistically significantly different according to post-hoc LSD test $(\mathrm{p} \leq 0.05)$. TEOAE SNR showed highly statistically significant difference in SNR between control group \&subgroups $(<20 y)$ \& $(\geq 30 y)$ at frequency band $4 \mathrm{kHz}$ in right and left ears, and between $(20-30 \mathrm{y}) \&(<20 \mathrm{y}) \&(\geq 30 \mathrm{y})$ subgroups at frequency band $4 \mathrm{kHz}$ in the right ears as shown in table 3 .

The amplitude of the otoacoustic emissions distortion products in study group was major in the frequency of $4 \mathrm{KHz}$, in both ear. The mean of the values of amplitude of frequency $4 \mathrm{KHz}$ was 19.56 in the right ear, 19.49 in the left ear in table 4.

The latency of waves I, III, and V, in all ears, lied within the normal range for our normative data for latency-intensity functions. When the control group results are compared with study group result, significant differences are explicit especially for wave I in table 5.

\section{Discussion}

In the current study the mean age is $21.40 \pm 10.10$ years in the control group and $25.26 \pm 12.58$ years in the study group without statistical significant difference between the two groups. Hence, both the groups did not fall into geriatric age group to exclude the degenerative factor of age. In this study $73.3 \%$ of study are females and $26.6 \%$ are males. In controls $80 \%$ are females and $20 \%$ are males. This difference in gender composition of the study group and control, which may be due to greater awareness and concern about cosmetic defect among females than among males, is statistically insignificant due to the match of control to the study group.

\section{Effects of vitiligo on hearing: PTA results}

In this study, audiological assessment showed that there is no statistical significant difference of hearing threshold between control group and vitiligo group at all frequencies from 250 to $8000 \mathrm{~Hz}$.

Our results disagree with the results of Fleissig et al. (5), Mahdi et al., ${ }^{(6)}$, Akay et al., ${ }^{(7)}$, Ardic et al., ${ }^{(8)}$, Aslan et al., ${ }^{(9)}$.

Mahdi et al., (6) found that audiometric thresholds were 
statistically greater in both ears of the patients with vitiligo at 2,4 and $8 \mathrm{kHz}$ compared with control subjects $(\mathrm{P} \leq 0.05)$. This findings strengthen the hypothesis that an alteration of the inner ear pigment cells might favor the occurrence of hypoacusis.

\section{Results of TEOAE}

In our study all controls showed bilateral pass response at all frequency bands. But in the study group $17 / 30(56.66 \%)$ showed bilateral pass response and $5 / 30(16,66 \%)$ of the cases showed unilateral pass (unilateral partial pass); The remaining $8 / 30$ (26.66\%) had bilateral partial pass response. The percentage of Pass response was $65 \%$ of ears [39/60 ears (34 ears of bilateraI pass) and (5 ears of unilateral pass)]. Percentage of Partial pass response was $35 \%$ of ears [21/60 ears (5 ears of partial pass) in addition to (16 ears of bilateral partial pass)]. When comparing the TEOAE findings in control and vitiligo groups in a frequency-specific way we found that SNR of TEOAEs were lower at the frequency band $4 \mathrm{KHz}$ in the study group than in the control group, which yield a highly statistically significant difference.

In the present study, the difference between control and study groups in TEOAE at frequency band $4 \mathrm{KHz}$ is due to outer hair cell dysfunction towards the base of cochlea which not apparent in PTA. This means that TEOAE is more sensitive in detecting the cochlear dysfunction than PTA. The same concept represented by Angrisani et al. (10) who found that TEOAE were absent in $66.7 \%$ of subjects with normal hearing so they concluded that TEOAE are sensitive test for detecting cochlear function before symptoms become manifest. Our result agree with Aslan et al. (9) who found a significant reduction in the amplitudes of TEOAEs only at 4 $\mathrm{KHz}$ in vitiligo group. When the values for reproducibility, stimulus intensity, stability and average TEOAE amplitude of patients and control groups, were compared no statistically significant difference was found.

The lost cochlear emission in the vitiligo group was previously explained by Schrott \& Spoendlin ${ }^{(11)}$ they stated that hypopigmentation disorders for a long duration may lead to degeneration of the outer hair cells beginning from the basal turn of the cochlea while inner ear hair cells remain structurally and functionally intact.

In our study the OHCs dysfunction which was detected by TEOAE can be explained by affection of the melanocytes in the inner ear which have multiple roles critical for hair cell survival, Including maintenance of the normal function of the stria vascularis and cochlea, the development of endocochlear potentials, and the ion and fluid gradient between the endolymph and the perilymph ${ }^{(12-14)}$.

In this study the decrease in the. TEOAE occurred at high frequency (at frequency band $4 \mathrm{KHz}$ ), which means that $\mathrm{OHC}$ affection occurred at the base of the cochlea. OHCs at the base of the cochlea seems be more susceptible to damage than those preset in the apex. This is supported by the finding of Steel et al. ${ }^{(15)}$ in their study of $\mathrm{Wv} / \mathrm{Wv}$ mutant mice, observed that inner ear hair cells were preserved, but outer hair cells in the basal half of cochlea were degenerating, possibly as a result of primary strial dysfunction. They also found that the organ of Corti looked reasonably normal in the apical turns, but there was degeneration of the hair cells towards the base.

\section{Results of DPOAE}

In this study all control subjects showed bilateral pass response. In the study group 19/30(63.33\%) showed bilateral pass response and $3 / 30$ $(10.00 \%)$ of the cases showed 
unilateral pass response (unilateral partial pass), the remaining $8 / 30$ (26.66\%) had bilateral partial pass response. The percentage of Pass response was $68 \%$ of ears [41/60 ears (38 ears of bilateraI pass) and (3 ears of unilateral pass)]. Percentage of Partial pass response was $32 \%$ of ears [19/60 ears (3 ears of partial pass) in addition to (16 ears of bilateral partial pass) ]. When comparing the DPOAE findings in control and vitiligo groups in a frequency-specific way we found that SNR of DPOAEs were lower at the frequency band $4 \& 8 \mathrm{KHz}$ in the study group than in the control group, which yield a highly statistically significant difference. Also there was a significant difference between value of amplitude of distortion otoacoustic emission in the frequency bands $4 \& 8$ $\mathrm{KHz}$ in the study group.

In the present study, the difference between control and study groups in DPOAE at frequency band $4 \& 8 \mathrm{KHz}$ is due to outer hair cell dysfunction towards the base of cochlea which not apparent in PTA. This means that DPOAE is more sensitive in detecting the cochlear dysfunction than PTA. Our result agree with Tosti et al. ${ }^{(16)}$ and Aydogan et al. (17) who found a significant reduction in amplitude and high percentage of abnormal DPOAE findings in vitiligo patients and there no significant effect of vitiligo subtype on cochlear function.

\section{Results of ABR}

In our study, ABR assessment to latency of component peak showed a significant difference in the latency of waves I, III, and V specially for wave I between control group and vitiligo group, wave I decrease more remarkably in vitiligo patients.

This results are in agreement with Hong et al., ${ }^{(18)}$ and Aydogan et al., ${ }^{(17)}$. hearing:
In our study, vitiligo patients were classified according to the type, of vitiligo into, generalized and localized type, Patients with generalized type were $25(83.3 \%)$ and those with localized type were 5 $(16.7 \%)$. As regard to TEOAE there was statistically significant difference in SNR between control group and generalized vitiligo and between control group and localized vitiligo at frequency band $4 \mathrm{KHz}$ in right and left ears.

Our results was in agreement with Fleissig et al. ${ }^{(5)}$ and Ardic et al. ${ }^{(8)}$.

\section{Effect of age of onset of vitiligo.}

In our study vitiligo patients were divided according to the age of onset of the disease into 3 groups (A, B and C). Patients with age of onset less than 20 years old (group A) they were 17 $(56.6 \%)$, those between 20 to 30 (group B) were $5(16.6 \%)$ and those more that and equal to 30 years old (group C) were $8(26.6 \%)$.

Comparing the results of TEOAE, SNR showed a statistically significant difference among the control and the three subgroups of age of onset of vitiligo at $4 \mathrm{KHz}$ frequency band. This statistically significant difference was found between control \& subgroup A, control group \& subgroup $\mathrm{C}$ on the right and left ears. While the right ears show also statistically significant difference between subgroups B \&A and between subgroups $\mathrm{B} \& \mathrm{C}$. The reproducibility $\%$ of TEOAE showed the same differences in SNR in addition to statistically significant difference between subgroup B and C. This means that patients with age of onset more than 30 have higher risk of developing auditory affection as they may be more vulnerable to oxidative damage caused by sever noise, ototoxic medication and even age -related hearing loss.

Our results was in agreement with Fleissig et al. (5) who founded a 
tendency towards increased severity of SNHL in older vitiligo patients and late onset of vitiligo.

\section{Effect of the duration of vitiligo} on hearing:

In our study vitiligo patients were classified according to duration of the disease into 2 categories less and more than 10 years. Patients with duration less than 10 were $19(63.33 \%)$ and those with the duration mare than 10 years were $11(36.66 \%)$. The results were in agreement with Fleissig et al. (5) and Sharma et al. ${ }^{(20)}$ who concluded that the duration of vitiligo does not, affect hearing, they found that no correlation between duration of vitiligo and hearing loss.

\section{Conclusion}

- Vitiligo has an effect on cochlear function and the affection is usually asymptomatic for long time.

- TEOAE\&DPOAE are sensitive tests for detecting cochlear dysfunction before symptoms become manifested as the TEOAE and DPOAE were impaired in $35 \%$ and $35 \%$ of the ears with normal hearing.

- $\quad$ The ABR finding concluded that melanin play a significant role in establishment and maintenance of structure and function of the auditory system and may modulate the transduction of auditory stimuli by the inner ear.

\section{References}

1. Kemp EH, Waterman EA, Weetman AP. Immunological pathomechanisms in vitiligo. Expert reviews in molecular medicine. 2001;3(20):1-22.

2. Majumder PP, Nordlund JJ, Nath SK. Pattern of familial aggregation of vitiligo. Archives of dermatology. 1993;129(8):994-8.

3. Moellmann G, Klein-Angerer S, Scollay DA, Nordlund JJ, Lerner
AB. Extracellular granular material and degeneration of keratinocytes in the normally pigmented epidermis of patients with vitiligo. The Journal of investigative dermatology. 1982;79(5):321-30.

4. Nordlund JJ, Lerner AB. Vitiligo. It is important. Archives of dermatology. 1982;118(1):5-8.

5. Fleissig E, Gross M, Ophir I, Elidan $\mathrm{J}$, Bdolah-Abram T, Ingber A. Risk of sensorineural hearing loss in patients with vitiligo. Audiology \& neuro-otology. 2013;18(4):240-6.

6. Mahdi P, Rouzbahani M, Amali A, Rezaii Khiabanlu S, Kamali M. Audiological manifestations in vitiligo patients. Iranian journal of otorhinolaryngology. 2012;24(66):35-40.

7. Akay BN, Bozkir M, Anadolu Y, Gullu S. Epidemiology of vitiligo, associated autoimmune diseases and audiological abnormalities: Ankara study of 80 patients in Turkey. Journal of the European Academy of Dermatology and Venereology : JEADV. 2010;24(10):1144-50.

8. Ardic FN, Aktan S, Kara CO, Sanli B. High-frequency hearing and reflex latency in patients with pigment disorder. American journal of otolaryngology. 1998;19(6):3659.

9. Aslan S, Serarslan G, Teksoz E, Dagli S. Audiological and transient evoked otoacoustic emission findings in patients with vitiligo. Otolaryngology--head and neck surgery : official journal of American Academy of Otolaryngology-Head and Neck Surgery. 2010;142(3):409-14.

10. Angrisani RM, Azevedo MF, Pereira LD, Lopes C, Garcia MV. A study on otoacoustic emissions and supression effects in patients with vitiligo. Brazilian journal of otorhinolaryngology. 2009;75(1):111-5. 
11. Schrott A, Spoendlin $H$. Pigment anomaly-associated inner ear deafness. Acta otolaryngologica. 1987;103(5-6):451-7.

12. Steel KP, Barkway C. Another role for melanocytes: their importance for normal stria vascularis development in the mammalian inner ear. Development. 1989;107(3):453-63.

13. Takeuchi S, Ando M. Inwardly rectifying $\mathrm{K}+$ currents in intermediate cells in the cochlea of gerbils: a possible contribution to the endocochlear potential. Neuroscience letters. 1998;247(23):175-8.

14. Tachibana M. Sound needs sound melanocytes to be heard. Pigment cell research. 1999;12(6):344-54.

15. Steel KP, Barkway C, Bock GR. Strial dysfunction in mice with cochleo-saccular abnormalities. Hearing research. 1987;27(1):11-26.

16. Tosti A, Bardazzi F, Tosti G, Monti L. Audiologic abnormalities in cases of vitiligo. Journal of the
American Academy of Dermatology. 1987;17(2 Pt 1):230-3.

17. Aydogan K, Turan OF, Onart S, Karadogan SK, Tunali S. Audiological abnormalities in patients with vitiligo. Clinical and experimental dermatology. 2006;31(1):110-3.

18. Hong CK, Lee $\mathrm{MH}$, Jeong $\mathrm{KH}$, Cha CI, Yeo SG. Clinical analysis of hearing levels in vitiligo patients. European journal of dermatology : EJD. 2009;19(1):50-6.

19. Gawkrodger DJ, Ormerod AD, Shaw L, Mauri-Sole I, Whitton ME, Watts MJ, et al. Vitiligo: concise evidence based guidelines on diagnosis and management. Postgraduate medical journal. 2010;86(1018):466-71.

20. Sharma L, Bhawan R, Jain RK. Hypoacusis in vitiligo. Indian journal of dermatology, venereology and leprology. 2004;70(3):162-4. 